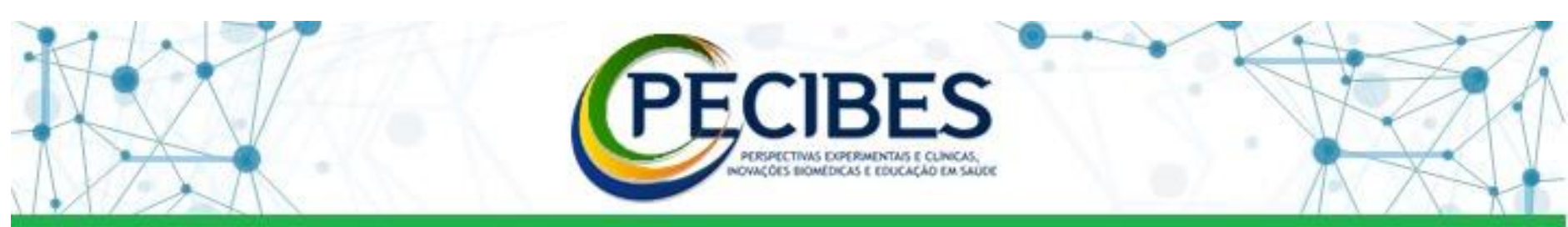

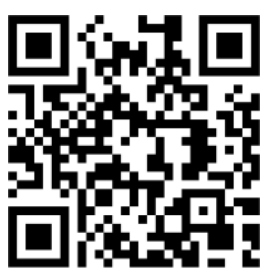

http://www.seer.ufms.br/inde x.php/pecibes/index

* Autor correspondente: Henrique Botelho Moreira, Universidade Federal de

Mato Grosso do Sul UFMS.E-mail do autor: moreirahike77@gmail. com

Descritores: Banco de Leite. Aleitamento materno.

Prematuridade.

Gestantes. Educação em saúde.

Key-words: Milk

Banks.

Breast Feeding.

Premature. Pregnant

Women. Health

Education.

Descriptores: Bancos de

Leche. Lactancia

Materna. Recien

Nacido

Prematuro. Mujeres

Embarazadas.

Educación

en Salud.

\section{Habilidades e competências em um Banco de Leite Humano: experiência de acadêmicos de enfermagem}

\author{
Skills and competences in a Human Milk Bank: experience of nursing students
}

Henrique Botelho Moreira ${ }^{1}$, Sara Jheniffer de Souza Lima ${ }^{1}$, Edilene Villalba dos Santos ${ }^{2}$, Leilaine de Oliveira Arakaki ${ }^{1}$, Layla Santana Corrêa da Silva ${ }^{3}$, Ana Paula de Assis Sales ${ }^{4}$.

1. Discente da Graduação de Enfermagem. Universidade Federal de Mato Grosso do Sul. Campo Grande, Mato Grosso do Sul, Brasil.

2. Enfermeira. Hospital Universitário Maria Aparecida Pedrossian. Campo Grande, Mato Grosso do Sul, Brasil.

3. Enfermeira Obstetra. Mestranda em Enfermagem pela Universidade Federal de Mato Grosso do Sul. INISA. Campo Grande, Mato Grosso do Sul, Brasil.

4. Enfermeira. Curso de graduação e pós-graduação em Enfermagem. INISA. Campo Grande, Mato Grosso do Sul, Brasil.

Introdução: o Aleitamento Materno Exclusivo (AME) durante os primeiros seis meses é o modo mais seguro, saudável, ecológico e traz inúmeras vantagens durante a infância, adolescência e vida adulta, como aumento da imunidade, diminuição de riscos para doenças cardiovasculares, obesidade e diabetes mellitus. Logo, é importante a capacidade de equipes de saúde incluírem a abordagem e apoio às mulheres e famílias sobre o tema, apoiando-nas em necessidades da adaptação ao papel de nutrizes, sejam de recém-nascidos a termo ou pré-termo. Ademais, durante a internação do binômio mãe-neonato, existem as dificuldades quanto a descida do colostro, exaustão e cansaço vivenciados no pós-parto imediato e mediato, preocupações maternas com outras situações familiares e fatores que interferem no estabelecimento da lactação. Objetivo: descrever a prática vivenciada por acadêmicos de enfermagem em projeto de extensão no Banco de Leite Humano (BLH) em hospital de ensino. Materiais e método: as práticas ocorreram no segundo semestre de 2021, no qual os acadêmicos com supervisão das enfermeiras preceptoras realizaram visitas ao alojamento conjunto detectando puérperas com dificuldades no estabelecimento da lactação, as quais receberam orientações e apoio técnico-científico, tais como: pega correta, prevenção de fissuras, massagem de Mohri para aumento da produção láctea e prevenção do ingurgitamento mamário. Ressaltou-se a forma de ordenha e armazenamento do leite humano para doação consciente, àquelas nutrizes que desejassem se tornar doadoras para os recém-nascidos pré-maturos do HUMAP/EBSERH. Conclusão: a vivência em um BLH, com preceptoria de enfermeiros, nutricionistas e técnicos de enfermagem, amplia a visão dos acadêmicos para a importância deste setor, que possui uma estrutura de captação, processamento e distribuição do leite humano para crianças prematuras. Dentre as vivências, observar as diferentes necessidades de nutrizes nas dificuldades no aleitamento materno e a oferta na formação de qualidade, demonstra a importância social do BLH na vida da sociedade sul-mato-grossense. 